\title{
Pemanfaatan Lingkungan dalam Pembelajaran Bahasa Indonesia
}

\author{
Ardina Fitria/19016150 \\ Universitas Negeri Padang-FBS \\ Ardinafitria2000@gmail.com
}

Setiap orang membutuhkan bahasa. Dalam berkomunikasi orang akan menggunakan bahasa. Indonesia merupakan negara yang memiliki banyak pulau yang tersebar. Keanekaragaman suku, ras, dan budaya, menyebabkan beragam bahasa daerah pula. Bahasa dan lingkungan memiliki hubungan yang erat karena lingkungan sangat bermanfaat dalam pembelajaran bahasa Indonesia. Dengan mempelajari bahasa Indonesia setiap orang yang berbeda daerah bisa berkomunikasi dengan mudah. Bahasa mempersatukan lingkungan orang timur dan lingkungan orang barat. Bukan hanya itu lingkungan dapat menjadi pendorong seseorang untuk bersemangat dalam mempelajari bahasa terkhususnya pada bahasa nasional sendiri. Menurut Mitsuki dan Lai (dalam Ramadhan et al, 2019) lingkungan menentukan dinamika kehidupan, kesehatan masyarakat, perkembangan perkembangan spiritual dan moral. Kerusakan lingkungan menghasil krisis ekologis yang akan menyebabkan serangkaian masalah dengan alam sumber daya, iklim populasi, makanan dan ekonomi, karena Manusia yang hidup saat ini dihadapkan dengan masalah lingkungan, umat manusia dikenal bahwa keberadaanya tergantung pada status lingkunganya. Lingkungan yang nyaman dapat memberi semangat seseorang dalam belajar. Lingkungan yang bersih memberikan manfaat yang besar dalam pembelajaran bahasa Indonesia. Menurut Buldur dan Omeroglu (dalam Ramadhan et al, 2019), pendidikan lingkungan penting untuk meningkatkan sikap dan kesadaran siswa terhadap lingkungan. Oleh sebab itu perlunya pembelajaran bahasa indonesia yang bertemakan lingkungan, sebab lingkungan dan pembelajaran bahasa indonesia memiliki kaitan yang erat.

Dalam penulisan karya sastra, tema lingkungan banyak diambil oleh penulis. Berdasarkan penelitian penulis, $73,3 \%$ orang setuju bahwa seseorang menciptakan sebuah karya puisi dengan mengamati lingkungan sekitar mereka. Serta $26,7 \%$ orang sangat setuju bahwa seseorang menciptakan sebuah karya puisi dengan mengamati lingkungan sekitar mereka. Mereka ingin lingkungan dapat tetap asri yang dipesankan melalui sebuah karangan yang indah. Tulisan itu dapat memberi manfaat terhadap lingkungan. Jadi adanya hubungan timbal balik dari pemanfaatan lingkungan dalam pembelajaran bahasa Indonesia. Ramadhan et al (2019) mengatakan bahwa pendidikan lingkungan penting untuk meningkatkan sikap dan kesadaran peserta didik terhadap lingkungan hidup. Guru juga mengupayakan untuk mengajarkan kepedulian terhadap lingkungan sejak dini, melalui pembelajaran bahasa indonesia. Sukma (2020) penanaman karakter penting ditanamkan sejak siswa masih duduk dibangku sekolah dasar. Ramadhan et al (2019) mengatakan bahwa pendidikan lingkungan penting untuk meningkatkan sikap dan kesadaran peserta didik terhadap lingkungan hidup. Sebab melalui bahasalah pesan dapat disampaikan dengan karya yang indah. Oleh sebab itu lingkungan dan 
bahasa indonesia memiliki peran yang sangat penting. Menurut Bergman B,G (dalam Ramadhan et al, 2019), guru memainkan peran penting dalam mengajarkan pendidikan lingkungan hidup. Misalnya, dalam pembelajaran bahasa Indonesia, guru dapat memberikan materi lingkungan kepada siswa agar siswa lebih memahami contoh yang pasti bisa ditemui di sekitarnya, atau dengan adanya materi lingkungan dalam pembelajaran bahasa Indonesia memudahkan siswa dalam menuangkan ide dalam bentuk tulisan, sehingga keterampilan menulis akan lebih baik lagi. Maka materi lingkungan dalam pembelajaran di sekolah sangat penting dalam pembelajaran bahasa Indonesia. Besar peran pemanfaatan lingkungan dalam pembelajaran bahasa Indonesia. Dengan bimbingan guru, siswa dapat lebih paham lagi besarnya pemanfaatan lingkungan dalam pembelajaran bahasa indonesia. Selain itu guru juga harus bisa menjelaskan hal yang memiliki hubungan dengan lingkungan seperti daur ulang sampah, proses terjadinya banjir yang di akibat oleh sampah. Agar lebih terlihat apa saja manfaat lingkungan dalam pembelajaran bahasa indonesia. Menurut Rivers W(dalam Ramadhan et al, 2019), guru bahasa adalah guru yang komplit, karena mampu memahami semua mata pelajaran yang dirangkap menjadi satu tulisan.

Pembelajaran yang bertemakan lingkungan akan gencar digerakkan oleh pemerintah. Karena memiliki banyak manfaat dalam pembelajaran. Khususnya dalam pembelajaran bahasa Indonesia. Upaya pemerintah melalui gerakan literasi. Karena dengan terus berliterasi, kemampuan membaca siswa akan terus meningkat. Sukma (2017) berpendapat kemampuan dalam berliterasi memiliki pengaruh yang signifikan terhadap keberhasilan siswa dalam belajar dan kehidupan sehari-hari. Selain itu literasi dapat berperan penting dalam pendidikan literasi siswa, melalui literasi sifat buang sampah pada tempatnya akan tertanam dengan sendirinya. Menurut (Indriyani et al., 2019) kegiatan literasi pada siswa perlu ditingkatkan terutama pada literasi baca tulis. Sejalan dengan itu (Martavia et al., 2016) menyampaikan memunculkan dorongan dan keinginan yang besar untuk terus membaca dengan menggerakkan seseorang untuk membaca sehingga kecintaan terhadap informasi, ide, hiburan, dan pengetahuan yang ada di dalam bacaan dapat tertanam. Peran guru dibutuhkan agar tercapainya tujuan pemerintah. Menurut Sukma (2012) dan Ramadhan et al (2019) guru berfungsi sebagai fasilitator dan manajer pembelajaran dalam proses pembelajaran. Sukma (2019) menyampaikan guru hendaknya memberikan motivasi kepada siswa. Dengan memberikan motivasi terkait pentingnya menjaga lingkungan. Diharapkan siswa mampu menerapkannya dalam kehidupan. Bukan hanya itu pengawasan dan bimbingan dari guru juga dibutuhkan. Diharapkan siswa dapat menumbuhkan sikap cinta terhadap lingkungan.

Selain dari sosok guru, orang tua juga berperan dalam pengajaran. Mengenai pemanfaatan lingkungan di kehidupan mereka. Lingkungan akan bisa menentukan bagaimana anak tersebut. Ramadhan et.al (2019) yang menyatakan bahwa pemerolehan bahasa pada anak dalam aspek fonologi dipengaruhi faktor lingkungan khususnya keluarga. Jika lingkungan anak buruk, maka pemerolehan bahasanya akan buruk pula. 26,7\% orang sangat setuju bahwa seseorang akan keliru berkomunikasi saat situasi formal disebabkan karena seringnya 
menggunakan bahasa daerah atau bahasa ibu. 66,7 \% orang setuju bahwa seseorang akan keliru berkomunikasi saat situasi formal disebabkan karena seringnya menggunakan bahasa daerah atau bahasa ibu. Dan 6,7 \% orang kurang setuju bahwa seseorang akan keliru berkomunikasi saat situasi formal disebabkan karena seringnya menggunakan bahasa daerah atau bahasa ibu. Orang tua harus berperan aktif dalam mendidik sang anak. Bukan hanya pendidikan formal yang berperan, orang tua juga tak kalah penting perannya. Kebiasaan anak akan terlihat saat mereka berada di situasi formal. Disitu terlihat bagaimana didikan orang tua mereka. Pemanfaatan lingkungan juga sangat diperlukan. Melalui pemilahan dan pemilihan lingkungan yang dapat berdampak positif. Jika lingkungan itu berdampak negatif dapat dijauhkan.

Sebelumnya ada angket yang sudah penulis buat dan sebarkan kepada para mahasiswa beserta pelajar. Ada 3,3\% pelajar dan 96,6\% mahasiswa. Dengan rentangan tahun lahir 2002 sampai 1999. Dari jumlah keseluruhan 30 responden yang ikut serta mengisi angket tersebut lebih dominan para responden perempuan dan dibandingkan para responden laki-laki dengan persentase $76,7 \%$ responden perempuan, $23,3 \%$ responden laki-laki.

Dari hasil penelitian yang dilakukan, penulis dapat menyimpulkan bahwa pemanfaatan lingkungan dalam pembelajaran bahasa Indonesia sangat penting. Hal ini dibuktikan melalui jawaban para responden bahwa pemanfaatan lingkungan dalam pembelajaran bahasa Indonesia sangat penting dan berpengaruh. Para responden secara tidak langsung menyatakan bahwa pemanfaatan lingkungan dalam pembelajaran bahasa indonesia merupakan dua hal yang berkesinambungan dan memiliki hubungan yang erat dan penting. Responden menyadari dan memahami bahwa lingkungan dan pembelajaran bahasa Indonesia memiliki banyak manfaat. Menurut penulis, hal ini sangatlah betul. Sebab dengan pemanfaatan lingkungan dalam pembelajaran bahasa indonesia, diharapkan pelestarian lingkungan dapat disuarakan. Bukan hanya itu karya sastra penulis banyak yang bertemakan lingkungan. Melalui karya sastra pesan tersirat akan dapat tersampaikan, bahwa menjaga lingkungan itu sangatlah penting. Memanfaatkan pembelajaran yang berteman lingkungan dalam pembelajaran bahasa Indonesia melalui karya sastra nan indah. 


\section{Kepustakaan}

Indriyani, V., Zaim, M., Atmazaki, A., \& Ramadhan, S. (2019). Literasi Baca Tulis Dan Inovasi Kurikulum Bahasa. KEMBARA: Jurnal Keilmuan Bahasa, Sastra, Dan Pengajarannya, 5(1), 108. https://doi.org/10.22219/kembara.vol5.no1.108-118

Martavia, R. F., Thahar, H. E., \& Asri, Y. (2016). Hubungan Minat Baca dengan Keterampilan Menulis Narasi Ekspositoris Siswa Kelas VII SMP Negeri 11 Padang. Jurnal Pendidikan Bahasa Dan Sastra Indonesia, 5(2), 363-369.

Ramadhan, S., Yasnur Asri, dan Vivi Indriyani . (2018). Learning Module Design Writing Argumentative Text Based Problem-Based Learning. Advances in Social Science, Education and Humanities Research, Vol 263: 194-200.

Ramadhan, S., Elfia Sukma, dan Vivi Indriyani. (2019). Environmental Education and Disaster Mitigation Through Language Learning. IOP Conference Series: Earth and Environmental Science, 314, p. 1-9.

Ramadhan, S., Elfia Sukma, dan Vivi Indriyani. (2019). Persepsi Guru terhadap Penggunaan Bahan Ajar Bahasa Indonesia dengan Perangkat Seluler dan Aplikasi Edmodo. Seminar Internasional Riksa Bahasa.

Ramadhan, S., Sukma E., dan Indriyani (2019). Environmental education and disaster mitigation through language learning. IOP Conference Series: Earth and Environmental Science, 314, pp. 1-9.

Sukma, Elfia. (2012). Pembelajaran Sastra yang Integratif Berbasis Kompetensi. International Conference on Languages and Arts, Halaman 432-436.

Sukma E, Ritawati M, dan Rizky A. (2017). Literacy Media Development in Improving Reading and Writing Skill of Early Class Students in Elementary School Padang Utara Padang. Advances in Social Science, Education and Humanities Research, Vol 118.

Sukma E. et.al. (2019). Problems in Oral Language Teaching in Primary School. Advances in Social Science. Education and Humanities Research, Volume 301.

Sukma E, dan VP Azrianti. (2020). Instilling Positive Characters in Students Using Folker in the Macromedia Application. Advances in Social Science, Education and Humanities Research, Volume 485. 